\title{
FORMAÇÃO SUPERIOR EM DANÇA NO BRASIL: PANORAMA HISTÓRICO-CRÍTICO DA CONSTITUIÇÃO DE UM CAMPO DE SABER*
}

\author{
Marcelo de Andrade Pereira \\ Universidade Federal de Santa Maria, Porto Alegre, RS, Brasil \\ JoÃo BatISTA LIMA dE SOUZA \\ Universidade Federal de Santa Maria, Palmeira das Missões, RS, Brasil
}

\begin{abstract}
Resumo: Este artigo apresenta um panorama histórico-crítico da constituição da dança como um campo de saber acadêmico no Brasil. Analisa as injunções entre arte, história e educação na formação superior em dança no país. Trata-se de uma pesquisa documental e bibliográfica.
\end{abstract}

Palavras-chave: Ensino da arte. Dança. Formação superior. Epistemologia.

A formação superior em dança no Brasil possui mais de meio século de tradição e de institucionalização no âmbito acadêmico. Se, por um lado, tal percurso se revela relativamente longínquo ou extenso, por outro, é possível perceber que a trajetória deste curso de graduação, apesar do tempo, não seguiu uma linha uniforme de desenvolvimento na busca por sua legitimação. A exemplo disso, um hiato de 28 anos - ou seja, praticamente três décadas assinalou o período compreendido entre a criação do primeiro e do segundo curso de graduação em dança no país, respectivamente o da Universidade Federal da Bahia (UFBA), em 1956, e o da Faculdade de Artes do Paraná (FAP), em 1984. Isso posto, pode-se afirmar que a formação superior do profissional de dança no Brasil teve uma história acidentada e, por vezes, acidental.

Para compreender esta formação, convém recuperar alguns elementos históricos presentes em sua constituição, os quais se ligam, por exemplo, a um sem número de concepções de dança, de profissional, de arte,

\footnotetext{
* Artigo recebido em 14/9/2013 e aprovado em 24/1/2014.
} 
de docência e de cientificidade presentes no delineamento dos objetivos deste curso de graduação e de seus respectivos perfis de egressos. A fim de levarmos a termo o intento, o presente texto se encarregará de descrever, de maneira pontual, o histórico da formação superior em dança no Brasil de forma a compor um panorama atualizado da mesma. Isso não quer dizer, entretanto, que o mesmo se reduza a uma mera descrição cronológica da inserção da dança no ensino superior. Trata-se de utilizar o recurso da síntese imagética de maneira a ensejar a visualização sugerida, em que a abordagem histórica não prescinde de sua crítica. Vale salientar que, por "panorama", entende-se a elaboração de uma imagem ampla e profunda, porém recortada, a qual pretende dar conta de toda uma paisagem que se dá a ver.

A tentativa de composição deste painel se passa, como mencionado, 56 anos após a instalação do primeiro curso de graduação na área, localizado na UFBA. Neste retrospecto considera-se o surgimento dos dois mais jovens cursos de formação superior em dança, quais sejam: o Bacharelado e a Licenciatura em Dança da Universidade Federal de Santa Maria (UFSM), criados em 2012 e cujas primeiras turmas principiaram suas atividades no primeiro semestre letivo de 2013.

\section{SISTEMA e-Mec COMO FONTE PRIMÁRIA DE DADOS}

Para percorrer os caminhos da formação superior em dança no país, primeiro foi necessário buscar fontes que permitissem o estabelecimento/ composição do panorama a ser vislumbrado. Em um momento inicial, os achados sobre a formação superior em dança foram obtidos nos endereços eletrônicos de algumas instituições nacionais com maior tradição no meio, o que se imaginava ser um canal eficiente para desvelar a trajetória em questão. Porém, a procura nestes locais se mostrou infrutífera no sentido de permitir saber quantas e quais são as instituições de ensino superior que, hoje, oferecem estes cursos de graduação. Isso porque tais instituições divulgam, em seus sites, tão somente um arrazoado de seus próprios cursos, os quais contêm informações gerais, não estabelecendo conexões com outros semelhantes - nem haveria razão para isso.

Realizou-se, também, uma consulta ao Instituto Nacional de Estudos e Pesquisas Educacionais Anísio Teixeira (INEP) à guisa de coletar os projetos políticos pedagógicos dos cursos de graduação em dança oferecidos no país; todavia, tais materiais não são disponibilizados pelo mesmo. A escassez de bibliografia que trate do tema contribuiu, além do mais, para dificultar a realização do estudo; poucas foram as remissões ao assunto encontradas tanto em artigos científicos, como em livros. Diferentemente da dança no 
contexto da educação básica (amplamente problematizada), pouca coisa se produziu até hoje, em termos de pesquisa acadêmica, que enfocasse a dança na educação superior no Brasil. Este, aliás, foi o fator preponderante para desencadear a presente investigação.

A viabilidade da pesquisa se apresentou por meio de um sistema eletrônico de informações disponibilizado pelo Ministério da Educação (MEC) na rede mundial de computadores, denominado e-Mec. Ele permite buscas por diversos indexadores, como nome da instituição, nome do curso, localização da universidade/faculdade, lugar/cidade de oferecimento do curso, dentre outros. Diante da abrangência da pesquisa, optou-se por organizá-la de maneira segmentada, objetivando uma compreensão que estivesse ao alcance não apenas de pesquisadores em dança e educação (ou, dito de outro modo, em arte e docência), mas também de estudantes que estão em vias de definir seu futuro profissional - para os quais esta compilação também pode oferecer respaldo, caso desconheçam as instituições que ofereçam cursos de graduação em dança e tenham interesse em frequentar um deles após a conclusão do ensino médio.

$\mathrm{O}$ e-Mec se constitui, a rigor, em um banco de dados virtual desenvolvido para o acompanhamento dos processos que regulam a educação superior no Brasil e por onde passam os pedidos de credenciamento e recredenciamento de instituições de ensino superior (bem como de autorização, renovação e reconhecimento de cursos). Trata-se de uma plataforma que reúne informações sobre todas as instituições e todos os cursos existentes, a partir da qual foi possível obter os dados primários da pesquisa. E o principal: são dados oficiais.

Com o grifo na palavra existentes, procuramos atentar para o fato de que o e-Mec considera apenas as graduações em funcionamento, ou seja, aquelas cujas atividades estão autorizadas. Contudo, o sistema não contempla cursos já extintos e/ou modificados, de onde deriva o segundo grifo, na palavra oficiais. Portanto, a existência, aqui, se apresenta como parcial ou incompleta. Todavia, no estudo de qualquer percurso espaço-temporal (não apenas este que aqui se anuncia e se apresenta), há que se considerar também, para além dos documentos oficiais, aquilo que no sistema não foi dito, catalogado, circunscrito, registrado; e, contudo, não deixou de ocorrer, acontecer. Sendo agudos, esses hiatos históricos são fortemente sentidos, deixando marcas profundas. Tal acontecimento indica o surgimento de algo novo ou diferente e em alguns casos, inclusive, chega a implicar o estabelecimento de uma nova ordem do saber.

A esse respeito, vale relembrar o pensamento de Foucault (1999, p. 55), para quem a análise histórica deve considerar os acontecimentos como 
que ampliando constantemente "o campo dos mesmos; neles descobr[indo], sem cessar, novas camadas, mais superficiais ou mais profundas; isola[ndose] sempre novos conjuntos onde eles são, às vezes, numerosos, densos e intercambiáveis, às vezes raros e decisivos". Tal como os eventos que possuem sua importância na constituição histórica de determinado objeto/domínio e que, por algum motivo, foram negligenciados no registro oficial. Estabelecemse, assim, "o 'lugar' do acontecimento, as margens de sua contingência, as condições de sua aparição" (Foucault, 1999, p. 56), onde

[...] certamente o acontecimento não é nem substância nem acidente, nem qualidade, nem processo; o acontecimento não é da ordem dos corpos. Entretanto, ele não é imaterial; é sempre no ânimo da materialidade que ele se efetiva, que é efeito; ele possui seu lugar e consiste na relação, coexistência, dispersão, recorte, acumulação, seleção de elementos materiais; não é o ato nem a propriedade de um corpo; produz-se com efeito dentro de e em uma dispersão material. (FoucAuLt, 1999, p. 57-58)

Para Cardoso (1995, p. 60), em paralelo, um "acontecimento pode ser considerado [...] uma abertura de um campo de possibilidades". Tal afirmação se pauta, claramente, pela teorização de Foucault, segundo o qual o acontecimento poderia ser percebido como o surgimento "de uma singularidade única e aguda, no lugar e no momento de sua produção" (p. 59).

Dito de outro modo, no que concerne ao nosso caso e mais particularmente à coleta de dados da pesquisa ora apresentada, ainda que o e-Mec não contemple o registro de cursos extintos ou modificados, isso não quer dizer que eles não tenham ocorrido ou que não tenham repercutido sobre a criação de outros cursos e até mesmo de uma concepção de dança e de profissional de dança formado em instituições de ensino superior. A este respeito, vale recobrar o caso do curso de Licenciatura em Dança da Universidade de Cruz Alta (Unicruz), no Rio Grande do Sul, que, criado em 2002, foi extinto em 2010. Comunicação oriunda do Núcleo Pedagógico da instituição, recebida em 11 de janeiro de 2013, após solicitação, informa que o curso encerrou suas atividades no segundo semestre letivo de 2010: "Salientamos que a última turma que ingressou no curso foi em 2007/01, após esta não houve mais demanda de alunos, nos três vestibulares posteriores (2008/2009/2010), que tornasse viável o oferecimento do curso. Então, em virtude disso o curso foi extinto.".

Outro fato que consideramos significativo e que não é abarcado pelos registros do e-Mec se refere à alteração da modalidade de Curso Superior de Tecnologia em Dança para Licenciatura em Dança na Universidade Luterana do Brasil (ULBRA), com sede em Canoas, também no estado do Rio Grande do 
Sul. O tecnólogo em dança da ULBRA foi criado em 2003, sendo o primeiro desta modalidade no Brasil, passando à condição de licenciatura em dança no ano de 2008. Verifica-se que tal alteração na nomenclatura e na estrutura do curso redireciona o sentido da formação em dança, seu campo de atuação, seus objetivos e o perfil do aluno egresso.

\section{ESTADO ATUAL DA FORMAÇÃO SUPERIOR EM DANÇA NO BRASIL}

O panorama da formação superior em dança no Brasil leva em conta as cinco regiões geográficas definidas pelo Instituto Brasileiro de Geografia e Estatística (IBGE), a saber: Norte, Nordeste, Centro-Oeste, Sudeste e Sul. Deste vasto universo territorial, de dimensões continentais, não poderiam surgir números que, também, não fossem superlativos. A realidade aponta para um curso que passa por um fenômeno de grande expansão, instalando-se em quase todos os centros urbanos do país, embora em alguns mais fortemente presentes.

Atualmente, 29 (vinte e nove) instituições de ensino superior (universidades, faculdades isoladas e centros universitários) que figuram no e-Mec oferecem o montante de 39 (trinta e nove) graduações em dança, nas habilitações de bacharelado e de licenciatura. Embora se tenha constatado, no início deste escrito, um intervalo de quase 30 anos entre a criação do primeiro e do segundo curso de graduação em dança no Brasil, a oferta de tal formação nas instituições de ensino superior aconteceu, nos anos subsequentes a este último, com certa regularidade.

Vale assinalar que, em conformidade com o e-Mec, outros hiatos históricos semelhantes àquele que separa a Universidade Federal da Bahia da Faculdade de Artes do Paraná - guardando-se, porém, as devidas proporções aconteceram apenas entre os anos de 1987 e 1990, somando quatro anos sem oferta de novos cursos; entre os períodos de 1991 a 1994 e 2004 a 2007, com dois anos de inércia em cada um dos dois momentos destacados; e entre 1997 a 2001, em que as referidas graduações foram criadas/instituídas à velocidade de uma por ano.

Diferentemente do que se pensava no início da pesquisa (que o curso ainda seria restrito a poucas instituições), registra-se, de fato, um significativo aumento de sua oferta. Pode-se afirmar que o nítido e vertiginoso crescimento da oferta de formação superior em dança no Brasil coincide com a implantação do Programa de Apoio a Planos de Reestruturação e Expansão das Universidades Federais (REUNI), especificamente nas instituições públicas federais, muito embora os cursos também ocorram em instituições de ensino superior privadas que, sabidamente, concentram maior número de vagas 
no ensino superior se comparadas às universidades/faculdades públicas, e que se orientam por demandas de mercado - tal como se pode deduzir, por exemplo, do comunicado anteriormente mencionado, vindo da Unicruz, como justificativa para o encerramento das atividades do curso.

O REUNI consiste em um programa governamental que tem por objetivo a criação de "condições para ampliação do acesso e permanência na educação superior, no nível de graduação, pelo melhor aproveitamento da estrutura física e de recursos humanos existentes nas universidades federais" (MEC, 2009). Foi instituído pelo Decreto n. 6.096, de 24 de abril de 2007, e integra o Plano de Desenvolvimento da Educação (PDE), com o qual o Governo Federal almeja atingir a meta de inclusão de $40 \%$ dos jovens na faixa etária de 18 a 24 anos no ensino superior até o ano de 2021.

Em consonância, criado para vigorar entre os anos de 2011 a 2020, o Plano Nacional de Educação (PNE) estabeleceu estratégias e metas para a educação em todo o país. Integram o PNE iniciativas como a do Programa Universidade para Todos (PROUNI), que concede bolsas de estudo de $50 \%$ e $100 \%$, e o Fundo de Financiamento Estudantil (FIES), que possibilita o custeio de mensalidades via financiamento bancário. Ambos se constituem importantes insumos para o desenvolvimento da formação superior no Brasil.

É necessário salientar, contudo, que tais ações governamentais têm sido alvo de muitas críticas, sobremaneira justificadas. A intenção deste estudo não é realizar uma reflexão sobre o pano de fundo político-ideológico de tais iniciativas governamentais e, sequer, discorrer sobre a qualidade e a efetivação dos objetivos estabelecidos pelas políticas públicas para a educação superior - tema constantemente abordado no âmbito da pesquisa em educação - mas, tão somente, assinalar o impacto da implementação de tais programas e, em especial, do REUNI na expansão da formação superior em dança no Brasil.

A partir de uma operação matemática denominada taxa de crescimento (pontuando a diferença existente entre um valor inicial e outro, final - considerando também os valores intermediários) demonstra-se no Gráfico 1, a seguir, a relação entre a implantação do REUNI e o crescimento do número de cursos de graduação em dança no Brasil. A contar do ano de 2007, 15 (quinze) novas graduações (sendo 12 na modalidade licenciatura e 3 na modalidade bacharelado) foram criadas: duas delas em 2007, duas no ano de 2008, três em 2009, quatro em 2010, duas em 2011 e duas no ano de 2012. Destas, apenas duas não estão localizadas em instituições públicas federais - um dos cursos criados pertence a uma instituição pública estadual e o outro, a uma instituição privada. 


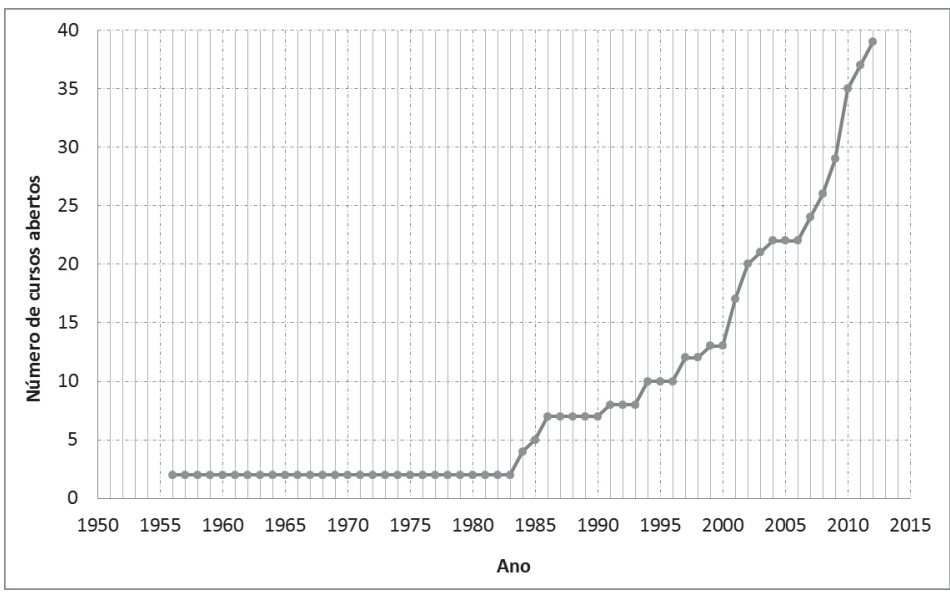

Gráfico 1 - Taxa de crescimento da formação superior em dança no Brasil. Fonte: Dados da pesquisa.

Numa perspectiva estatística, a partir desta realidade representacional pode-se apontar que, do total de graduações em dança existentes desde a criação do primeiro curso no Brasil, 15 (quinze) delas, ou 38,46\%, foram criadas nos últimos seis anos - um número expressivo, portanto. Sob outra ótica, informa-se que ao longo de meio século (1956-2006) ocorreu a criação de 24 (vinte e quatro) cursos, somando $61,54 \%$ do total. Isso equivale a dizer que, nos seis anos anteriormente mencionados (2007-2012), houve a criação, em média, de 2,5 cursos ao ano. A partir do mesmo raciocínio, considerando o período anterior (que totaliza cinco décadas), a média de criação de novos cursos foi de 0,48 ao ano. Ou seja, um curso criado a cada dois anos, aproximadamente, considerando a influência da grande lacuna referida sobre o número médio.

Como desdobramento deste jogo de números observa-se que, hipoteticamente, caso o último indicativo $(0,48)$ se mantivesse durante todo o período, isto é, 56 anos, teríamos hoje cerca de 26 cursos de graduação em dança em todo o território nacional. Supondo que o primeiro indicativo $(2,5)$ fosse utilizado como razão para a multiplicação, haveria, nos dias atuais, 125 cursos superiores de dança no Brasil.

Em uma tentativa de conhecer o caráter da formação superior em dança, indagou-se quanto ao local em que os cursos são oferecidos, ou seja, se ocorrem em instituições públicas - mantidas pelos governos estadual e, principalmente, pelo federal - ou em instituições privadas. Pode-se perceber 
que a maior parte das instituições pesquisadas são públicas. Dentre essas, a maioria tem a origem de seus recursos na União, posto que são universidades federais. Do total de instituições pesquisadas, 21 (vinte e um) cursos de dança (72\%) se concentram nas universidades/faculdades públicas (federais ou estaduais) e 08 (oito) deles (28\%) são oferecidos em instituições particulares/ privadas. Assim, fica claro que a maior parte das graduações não se concentra na iniciativa privada.

O estabelecimento do panorama histórico-crítico da formação superior em dança no país implica, também, realizar apontamentos específicos no plano das modalidades de habilitação que o curso oferece, a licenciatura e o bacharelado. Para tratar da questão pertinente às habilitações, é interessante migrar desta discussão, centrada no ensino superior, para outra - que se relaciona com a educação básica. Na legislação educacional são encontrados alguns indicativos que, como via de suposição, podem esclarecer e justificar a ocorrência, circunstancial, dos próximos números a serem apresentados.

A Lei de Diretrizes e Bases da Educação Nacional n. 9.394/96 - lei orgânica e geral da educação brasileira que, como o próprio nome menciona, explicita as diretrizes e bases da organização do sistema educacional no país - e, posteriormente, a publicação dos Parâmetros Curriculares Nacionais (PCNs), junto, ainda, das Diretrizes Curriculares Nacionais (DCNs) para cursos de graduação, se constituíram em importantes ações governamentais regulamentadoras que contemplaram não apenas os processos concernentes à educação básica, mas, também, a formação de professores em nível superior, nos cursos de licenciatura. $\mathrm{O}$ advento das atualizações promovidas na legislação educacional permitiu uma reconfiguração e transformação deste cenário, atualizando-o.

Contudo, mesmo a dança sendo apontada como uma das formas mais antigas - e registradas - de expressão do homem (FARO, 1986; MENDES, 1987; Ossona, 1988), sua validade como ação educativa somente vem a ser referendada nos últimos anos, no Brasil, depois de outras linguagens artísticas que, no decurso da história, aparecem como sendo posteriores à utilização do movimento corporal como ato representativo/performativo. Assim, a legitimidade da dança no contexto do processo formativo é, a despeito dessas considerações, ainda problemática. Reside, portanto, na figura do profissional que irá atuar em dança e educação o encargo de enfatizar e comprovar suas potencialidades para a educação de crianças e adolescentes, justificando nesse processo sua credencial de professor de dança. Tal realidade implica 
indagar quem pode ministrar aulas de dança na escola. A exemplo disso, de acordo com Strazzacappa e Morandi (2011, p. 8),

[...] a nova Lei de Diretrizes e Bases da Educação Nacional (LDB) 9.394/96 prevê que o ensino de arte passa a ser obrigatório na educação básica, e os Parâmetros Curriculares Nacionais (PCNs) da área apontam que as quatro linguagens artísticas (música, dança, teatro e artes visuais) devem ser contempladas. Se, por um lado, a alteração da legislação apresenta um avanço na formação do cidadão, por outro, não deixa claro qual o profissional habilitado a ministrar esse componente curricular.

A partir do momento em que a legislação contempla e (re)qualifica a dança no âmbito da educação básica (ensino fundamental e médio) é que se inicia um processo de instauração, de fato, de diferentes perfis de atuação cujas particularidades põem, de um lado, a licenciatura e, de outro, o bacharelado. Os possuidores do diploma de licenciado seriam os profissionais capacitados para o desenvolvimento do componente curricular dança na educação básica. Entretanto, ainda que a dança constitua um campo específico de atuação docente, ela se encontra vinculada a áreas que abrangem formas distintas de expressão artística/corporal. Os PCNs específicos de arte, por exemplo, contemplam a dança em um conjunto de que participam, ainda, o teatro, as artes visuais e a música.

A mesma publicação, porém, nos conteúdos de educação física, classifica a dança no grupo das práticas da cultura corporal de movimento (jogos e brincadeiras, esporte, dança, ginástica e lutas), estabelecendo outra interface para a área. Neste plano, segundo Darido e Rangel (2005, p. 202), considera-se a dança como "fonte de autoconhecimento, e não como técnica acabada". A aula de educação física, dentre seu vasto leque de conteúdos, pode, no entendimento das mesmas, também dinamizar atividades voltadas à orientação da exploração corporal do estudante a partir da dança, supondo que "ele vai conhecer as diversas manifestações dançantes [...], discuti-las e atentar para a criatividade de suas possibilidades de movimentação corporal, transformando-as em dança" (DARIDO; RANGEL, 2005, p. 202).

Independente da forma como a dança se faz presente na educação infantil e no ensino fundamental e médio, e a despeito de ela ser contemplada tanto nos conhecimentos/habilidades relativos às artes como nos concernentes à educação física, o fato é que a realidade educacional torna o problema mais complexo, já que a dança escolar ainda é produto de dúvidas e incertezas entre os professores das duas áreas; ou melhor, das três áreas mencionadas (artes, dança e educação física). Isso permite abrir a aba do problema relativo 
à matriz epistemológica dessas distintas formas de apropriação da dança, seja como arte, seja como movimento corporal instrumental.

No contexto do ensino superior a situação da formação em dança também passou a se reconfigurar com atualizações promovidas na legislação educacional específica. Tal fato pode ter contribuído para o distanciamento entre a atuação artística e o ofício do professor, todavia estabeleceu fronteiras que até então não estavam circunscritas nem na prática, nem no campo conceitual; fronteiras estas corporificadas na formação do bacharel e do licenciado. O Parecer CNE/CES n. 0195/2003, aprovado em 5/8/2003 e publicado no Diário Oficial da União no mês de fevereiro do ano seguinte, definiu dois loci com campos de atuação distintos, cada um deles relacionado a conhecimentos específicos, para os cursos de graduação em dança em todo o território brasileiro.

Convém analisar o próprio documento com relação a esse aspecto. Ele explicita as bases orientadoras para a formação superior em dança no Brasil. Diz o mencionado parecer:

O curso de graduação em Dança deve propiciar uma formação profissional com duas vertentes: a primeira comprometida em formar o profissional envolvido com a produção coreográfica e o espetáculo de dança e a outra voltada não só para o profissional que trabalha com a reprodução do conhecimento como também para o que trabalha com o ensino das danças, especialmente para portadores de necessidades especiais ou ainda que utiliza a dança como elemento de valorização, de autoestima e de expressão corporal, visando a integrar o indivíduo na sociedade, consolidados em cada movimento e em cada plasticidade, na dança em educação especial, a harmonia dos componentes motor, cognitivo, afetivo e emocional. (MEC/ CNE, 2003, p. 4-5)

Em vista disso, e diante da constatação de que a maior parte das habilitações concedidas aos egressos dos cursos de dança brasileiros é de licenciatura, entre todo o universo de instituições pesquisadas, pontua-se o pendor das instituições pela formação de professores de dança para atuar na educação básica ou, nas palavras do próprio parecer citado, no ensino das danças, muito embora esta dedicação mais explícita das universidades em formar docentes de dança não garanta a inserção efetiva (e de direito) destes no mundo do trabalho - já que, no que tange à contemplação da área pela LDB, poucos são os registros de concursos para professores de dança nas escolas estaduais e municipais até o momento. Do total de cursos, 26 (vinte e seis, ou seja, 67\%) são de licenciatura e 13 (treze, somando 33\%) de bacharelado. 
Ao procurar desdobrar a análise quanto à modalidade de formação, é possível apontar qual área geográfica forma mais professores de dança ou mais artistas da dança. A região que concentra o maior número de cursos de licenciatura (formação de professores) é a Sudeste, com 10 (dez) ocorrências. O mesmo se percebe relacionado aos cursos de bacharelado (formação de artistas), cuja maioria, 8 (oito) cursos, está concentrada também nesta região. O contrário deste movimento é verificado na região Norte, onde 3 (três) ocorrências são registradas: existem, lá, dois cursos de licenciatura e um de bacharelado, em que pese haver apenas duas instituições de ensino superior inseridas no universo de sete estados que compõem a região. A disponibilização/disposição dos cursos de licenciatura é superior aos cursos de bacharelado em todos os estados, nas cinco regiões brasileiras. Nas regiões Sul e Nordeste ocorrem números similares: a primeira, com três estados, possui cinco cursos de formação docente na área; e a segunda, com seis estados, tem seis cursos relacionados. Na região Centro-Oeste, compreendendo três estados mais o Distrito Federal, nenhuma instituição oferece o curso na modalidade de bacharelado.

\begin{tabular}{|l|c|c|}
\hline Região & Licenciatura & Bacharelado \\
\hline Norte & 02 & 01 \\
\hline Nordeste & 06 & 02 \\
\hline Centro-Oeste & 03 & - \\
\hline Sudeste & 10 & 08 \\
\hline Sul & 05 & 02 \\
\hline
\end{tabular}

Quadro 1 - Divisão regional por modalidade de formação.

Fonte: Dados da pesquisa.

Mencionou-se há pouco a definição do que seria uma imagem panorâmica. Uma de suas características, também referida, é a amplitude da cena. Em se tratando do Brasil, com sua gigantesca dimensão territorial, o que o coloca entre um dos maiores do mundo em termos de área de acordo com o IBGE, o panorama da formação superior em dança, definitivamente, conduz o olhar do observador na direção de um horizonte tão amplo quanto as fronteiras brasileiras. Em vista disso, deduz-se que a localização dos cursos de graduação em dança não se apresenta distribuída uniformemente - ou harmonicamente - nas cinco regiões geográficas. É sabido que há áreas com maior densidade populacional no Brasil, assim como em determinados locais 
os únicos habitantes se encontram (de certa forma até isolados) em aldeias indígenas ou pequenos povoados.

No que concerne à localização dos cursos de formação superior em dança, esta pulverização é disforme. Todos os cursos nas regiões Norte, Nordeste e Centro-Oeste ocorrem em instituições públicas. Na região Sudeste, há uma proporção relativamente próxima no que diz respeito a cursos em instituições públicas e privadas. A maior concentração da graduação em todo o Brasil se encontra na região Sudeste, distribuída entre seus quatro estados, mas com especial aglutinação nos estados do Rio de Janeiro e São Paulo, onde é reconhecida a gigantesca densidade populacional. No Sul, dos seis cursos existentes apenas um é privado e está localizado no Rio Grande do Sul. No âmbito das instituições públicas, $9 \%$ estão na região Norte; $26 \%$ na região Nordeste; $13 \%$, no Centro-Oeste; 30\%, no Sudeste; e 22\%, no Sul. Já dentre as privadas, a proporção é de $83 \%$ no Sudeste e $17 \%$ no Sul.

\begin{tabular}{|l|c|c|}
\hline Região & Público & Privado \\
\hline Norte & 02 & - \\
\hline Nordeste & 06 & - \\
\hline Centro-Oeste & 03 & - \\
\hline Sudeste & 07 & 05 \\
\hline Sul & 05 & 01 \\
\hline
\end{tabular}

Quadro 2 - Localização regional por caráter das instituições pesquisadas. Fonte: Dados da pesquisa.

Ao mesmo tempo em que residem na matriz epistemológica os nós górdios que fixam a concepção e a aplicação da dança no ambiente escolar questão já abordada neste trabalho - também na formação superior este assunto se constitui em objeto de acaloradas discussões. A implantação de um curso superior de dança requer a definição de um lócus, de uma casa para abrigá-lo. Isso implica estabelecer qual unidade acadêmica/departamento irá receber o curso. Ficaria ele vinculado ao mesmo lugar de acontecimento do curso de Educação Física, compartilhando de suas concepções de corpo, docência, educação e movimento? Deveria ele estar conectado aos cursos de artes, comungando das mesmas concepções de arte, de artista, de performance em dança?

A intenção não é responder, aqui, a nenhuma destas perguntas; apenas localizar o que pode ser percebido quando da indagação sobre os 
locais de funcionamento dos cursos superiores de dança dentro de cada instituição onde ocorrem - apenas um dos itens, dentre tantos, contemplados na tarefa de elaboração do panorama histórico-crítico que se constitui neste texto. Todavia, se no âmbito do ensino superior é possível antever uma espécie de tensão no que tange à definição das matrizes epistemológicas dos cursos de licenciatura e bacharelado em dança (gerando pendores que ora confluem para a saúde, ora para as artes), no âmbito da prática profissional cotidiana esta tensão se transforma em fricção: são públicas as disputas de pertencimento e de legitimidade que gravitam entorno do assunto. Afinal, do ponto de vista legal, a quem pertence a dança? Proposição polêmica, já que mais de uma área tem, na dança, seu ofício.

O Conselho Federal de Educação Física (CONFEF) e o Conselho Regional de Educação Física (CREF) disseminam o discurso institucional de que se constituem (o primeiro em nível nacional e o segundo em nível estadual) como entidades reguladoras de todas as profissões que trabalham com atividades físicas. A dança, aqui, juntamente com a prática de ginástica, musculação, e tantas outras, também é vista como exercício físico. O zelo das duas entidades reside na intenção de proteger quem as realiza de danos à saúde diante da orientação de pessoas que não tenham condições de dinamizá-las adequadamente. O exercício, de início benéfico, tornar-se-ia maléfico.

Segundo Pereira e Hunger (2006), a educação física e a dança são áreas distintas, possuidoras de corpos específicos de conhecimento - o que se observaria pela existência de cursos de graduação e de pós-graduação tanto de um, quanto de outro, no país. Para as autoras, "esta distinção vem acompanhada de disputas de ambas as áreas pelo estabelecimento de suas fronteiras quanto ao seu próprio objeto de estudo e ao seu campo de atuação na sociedade" (Pereira; Hunger, 2006, p. 1). Paralelamente, Ferraz (2000), comentando as distinções visíveis entre as duas áreas, menciona que existe

[...] uma tensão inegável entre os profissionais destas duas áreas, ou seja, os intelectuais e professores de dança consideram os profissionais da educação física incapacitados para trabalhar este conteúdo, por o fazerem, geralmente, de maneira acrítica e superficial, enfatizando a abordagem tecnicista da mesma, e do outro lado, os profissionais da educação física se consideram no total direito em desenvolver este conteúdo devido a sua formação acadêmica, por ter estudado anatomia, cinesiologia, atividades expressivas e lidar diretamente com o movimento. (p. 14-15)

Há que se considerar, neste prisma, a Resolução n. 046/2002 do Conselho Federal de Educação Física, que instituiu a obrigatoriedade de 
registro dos profissionais que atuam nas diferentes áreas que trabalham com o corpo. Percebendo-se neste contexto, vários profissionais da dança foram contrários à normativa, culminando no Projeto de Lei n. 7.370/2002, que libera a dança (episteme arte) da fiscalização do conselho. De outro lado, o bailarino, o coreógrafo, o dramaturgo, ensaiadores e o maître de ballet passaram a integrar a categoria dos artistas (criada com a instituição da Lei n. 6.533/1978), os quais foram, posteriormente, também catalogados pela Classificação Brasileira de Ocupações (CBO), na categoria de artistas da dança. Menciona-se que a atenção e o esforço de fiscalização do CONFEFF, conforme declarações de seu próprio presidente ainda no ano de 2009, ${ }^{1}$ não se volta em direção a quem pensa e trabalha a dança como arte e, sim, à dança como atividade física praticada, por exemplo, em academias. Seria uma questão, portanto, de delimitar o que é esporte, exercício físico - e o que não é.

Disputas de pertença à parte, estando claras as fronteiras e os atravessamentos ocorridos, no que concerne ao campo epistemológico da dança como atividade física/saúde e considerando sua inserção no ambiente escolar (educação formal), é preciso levar em conta que ela sempre esteve presente nos educandários. "O fato é que a dança é trabalhada há muito tempo dentro da área de educação física anos antes de ela ser reconhecida/ institucionalizada como linguagem da arte" (OLIVEIRA, 2010, p. 112). Integrando o conjunto das manifestações da cultura corporal de movimento, a dança participa, na educação física, do mesmo conjunto que os jogos, as lutas e a ginástica. Considerada como tal, de acordo com os conteúdos da educação física nos Parâmetros Curriculares Nacionais (MEC, 2006), abarca as variadas manifestações culturais brasileiras, que carregam uma multiplicidade tão grande quanto a extensão territorial do país.

No âmbito do ensino superior, do total de cursos de graduação em dança existentes no Brasil, somente quatro estão vinculados à área da saúde, funcionando em unidades/departamentos onde também ocorre o curso de educação física, sendo estes os casos da Universidade Federal do Rio Grande do Sul (UFRGS), da Universidade Federal de Goiás (UFG), o da Universidade Luterana do Brasil (ULBRA) e o da Universidade Federal de Santa Maria (UFSM). Os demais, tanto as habilitações de bacharelado como as de licenciatura, possuem concepções de dança relacionadas à arte e à cultura, estando vinculados a departamentos, setores e núcleos de arte e/ou educação nas diversas universidades pesquisadas. Registra-se um caso à parte: o da UFSM, cuja licenciatura acontece junto ao Centro de Educação Física e Desportos, ao passo que o bacharelado está alocado no Centro de Artes e Letras, muito embora ambos os cursos compartilhem espaços e possuam algumas disciplinas em comum. 
Pode-se dizer, a respeito das disputas envolvendo a dança nos âmbitos da educação básica e da atuação em ambientes não formais de ensino, que se trata de uma questão relacionada, diretamente, com as matrizes epistemológicas que se conectam a este campo de saber, que é - múltiplo. Já no seio da universidade é possível cogitar que as tensões oriundas dos cursos de graduação em dança podem indicar disputas entre distintas unidades acadêmicas, refletindo embates de poder no interior das relações nas instituições de ensino superior. Enquanto, no primeiro caso, a questão trata de modos de compreensão da dança, no segundo indica um suposto empenho por reter o curso em determinado departamento e não em outro, o que, do ponto de vista das políticas educacionais para a educação superior, pode impactar positivamente o desempenho deste frente aos demais no afã de angariar um maior número de matrículas, tanto no setor privado, como no público.

Neste aspecto, seria possível deliberar sobre a matéria a partir de Foucault, refletindo que as tensões oriundas dos entrecruzamentos mencionados se elaboram no plano das relações de saber/poder. Entendendo que todas as relações humanas são permeadas pelo poder - e nelas o poder pode significar opressão, mas também produção - a perspectiva foucaultiana permite esquadrinhar com propriedade a luta por associação da formação superior em dança em um determinado departamento universitário e não em outro. O sentido do poder, aqui, se aproxima do de propriedade, estabelecendo lugares a serem ocupados pelos sujeitos em uma determinada rede de relações, concedendo autoridade não apenas a eles, mas aos discursos que pronunciam.

O discurso [...] não é simplesmente aquilo que manifesta (ou oculta) o desejo; é, também, aquilo que é o objeto do desejo; e visto que [...] o discurso não é simplesmente aquilo que traduz as lutas ou os sistemas de dominação, mas aquilo por que, pelo que se luta, o poder do qual queremos nos apoderar. (FouCAULt, 1999, p. 10)

O poder de que se quer apoderar referido pelo filósofo francês se conecta com o poder de poder ordenar o estabelecimento das coisas ou, em outras palavras, com o poder de estabelecer o que é válido ou não. Deriva daí a necessidade de se trabalhar com outro conceito de Foucault, a verdade. Para ele, a verdade é um efeito das relações de poder, sendo também histórica e dependente de um conjunto de forças. A verdade seria aquilo que as pessoas que estão numa determinada relação de poder impõem como verdadeiro num determinado momento histórico, ou o que estabelece como preceitos a serem seguidos. Tais preceitos se transfiguram em predicados/credenciais que conferem autoridade ao discurso de quem os pronuncia e, como nem 
tudo é insidiosamente doce na relação com o outro, conforma e interdita os demais, podendo, inclusive, sujeitar outrem à rejeição.

Cabe uma observação: diferentemente da concepção de discurso própria da Análise de Discurso empreendida pelos analistas da língua, a "distinção [aqui] rompe com os sentidos correntes do campo da linguística, calcados no binarismo significante-significado" (SOMmer, 2007, p. 58). Como sendo nosso operador teórico, Foucault não caminha, quando trata do tema, por entre aquilo que possa estar camuflado no discurso. Fischer (2001) explicita tal observação ao assinalar que, na análise do discurso à maneira foucaultiana, "nada há por trás das cortinas, nem sob o chão que pisamos. Há enunciados e relações, que o próprio discurso põe em funcionamento. Analisar o discurso seria, pois, dar conta exatamente disso: de relações históricas, de práticas muito concretas, que estão 'vivas' nos [próprios] discursos" (p. 198-199).

Nas palavras de Foucault (1999), o discurso seria nada além do que a reverberação de uma verdade que nasce diante dos olhos.

E, quando tudo pode, enfim, tomar a forma do discurso, quando tudo pode ser dito e o discurso pode ser dito a propósito de tudo, isso se dá porque todas as coisas, tendo manifestado e intercambiado seu sentido, podem voltar à interioridade silenciosa da consciência de si. (p. 49)

O discurso como indicativo de verdade assinala caminhos em direção a uma prática, algo que se presentifica naquilo que falamos, veiculado como verdade, mas não somente nisto. $O$ discurso em Foucault é, por assim dizer, o que constitui o sujeito; porém, este não constitui o discurso: cabe a cada um se colocar em uma posição de sujeito, assumindo o arranjo, inserindo-se no esquema e sendo atravessado pelo discurso, reverberando-o. Cabe lembrar, no sentido do estudo ora apresentado, o conselho de Fischer (2001) quando da realização da análise do discurso em questões da educação, de que "é preciso ficar (ou tentar ficar) simplesmente no nível de existência das palavras, das coisas ditas. Isso significa que é preciso trabalhar arduamente com o próprio discurso, deixando-o aparecer na complexidade que lhe é peculiar" (p. 198).

Mas, afinal, o que está presente no discurso em relação à sua análise histórica ou análise das minúcias históricas que constituem um discurso? Se pudéssemos submetê-lo a um filtro, que extrato dele surgiria? Foucault (1997) nos responderia que é desse modo que chegamos aos enunciados, que, "diferentes em sua forma, dispersos no tempo, formam um conjunto quando se referem a um único e mesmo objeto" (p. 36). Tomando emprestado o conceito do autor, teríamos na história da formação superior em dança um 
objeto. Sua análise trataria de definir os enunciados conexos que ecoam nos projetos político-pedagógicos sob a forma de enunciações - aquilo que é escrito e que constitui a organização teórico-metodológica de cada curso.

Do discurso emana uma necessidade de adaptação a uma ordem. É esta conformação que indica o que é e o que não é pertinente a determinado campo. E ela se dá pelo enunciado, que cumpre a tarefa de falar (falar aqui é diferente de propor) por um discurso, mas que não sobrevive em um só campo do conhecimento; o enunciado é livre. A exemplo dessa liberdade, podemos citar dois enunciados que se fazem presentes no campo da dança. Um deles é oriundo da arte - que a considera como expressão artística; outro emana da educação física - que a considera utilitariamente para a manutenção da saúde do corpo. Daí a importância de, no estudo do discurso, observar os enunciados que se ligam a ele, já que estes pressupõem domínio de objetivos específicos.

O empreendimento inicial da pesquisa (uma reunião de informações estatísticas que permitiram a compreensão, atualizada, do cenário da formação superior brasileira em dança) possibilitou conhecer sua trajetória histórica, mas também revelou atravessamentos entre saberes e poderes, seja via diferenciação nas habilitações concedidas, seja via políticas institucionais para o curso. A investigação destacou a institucionalização da dança como campo de saber universitário e seu oferecimento nas escolas de educação básica, o qual é regulado pela legislação educacional vigente. Muito embora isso requeira um determinado profissional, há que se pensar, também, a inserção deste sujeito no mercado.

Ao dirigirmos o olhar ao referido panorama, percebeu-se uma formação que possui aproximadamente seis décadas de existência, tendo iniciado na Universidade Federal da Bahia. Posteriormente, a criação do curso em outras instituições aconteceu de maneira irregular ao longo do tempo e, especialmente com a implementação do programa governamental denominado REUNI, registrou-se um vultoso crescimento do mesmo, acentuando a aperiodicidade. Tal fenômeno serve, para além do propósito estatístico, como indicativo da evolução e do estabelecimento da dança como um campo específico e legítimo de saber, cuja problematização é sempre fecunda.

THIRD LEVEL DANCE EDUCATION IN BRAZIL: A HISTORICO-CRITICAL OVERVIEW OF THE ESTABLISHMENT OF A FIELD OF KNOWLEDGE

ABSTRACT:This article presents a historico-critical overview of the establishment of dance as a field of academic knowledge in Brazil. It analyzes the relationship between art, 
history and education in Third Level dance education in this country. It is based on a documental bibliographical research.

KEY WORDS: Art education. Dance. Third level education. Epistemology.

\section{LA FORMACIÓN SUPERIOR EN DANZA EN BRASIL: PANORAMA HISTÓRICO-CRÍTICO DE LA CONSTITUCIÓN DE UN CAMPO DE SABER}

ResUmen: Este artículo presenta un panorama histórico-crítico de la constitución de la danza como un campo del saber académico en Brasil. Se analizan las imposiciones del arte, la historia y la educación en la formación superior en danza en el país. Se trata de una investigación documental y bibliográfica.

Palabras claves: Educación artística. Danza. Educación superior. Epistemología.

\section{NOTAS}

1. Por exemplo, conforme entrevista disponível em: <http://idanca.net/lang/pt-br/2009/07/15/profissionais-da-danca-comemoram-mais-uma-conquista/11523>. Acesso em: 15 jan. 2013.

\section{REFERÊNCIAS}

CARDOSO, I. de A. R. Foucault e a noção de acontecimento. Tempo Social: Revista de Sociologia da USP, São Paulo, v. 7, n. 1-2, out. 1995.

DARIDO, S. C.; RANGEL, I. C. A. (Coord.). Educação física na escola: implicações para a prática pedagógica. Rio de Janeiro: Guanabara Koogan, 2005.

FACULDADE DE ARTES DO PARANÁ (FAP). Projeto Pedagógico do curso de Dança - Bacharelado e Licenciatura. Disponível em: <http://www.fap.pr.gov.br/modules/ conteudo/conteudo.php?conteudo=12>. Acesso em: 3 mar. 2013.

FARO, A. J. A dança no Brasil e seus construtores. Rio de Janeiro: Fundacen, 1988.

FERRAZ, A. C. A. M. A arte de dançar nas aulas de Educação Física: para além de suas fronteiras em busca da construção da cidadania. Monografia (Licenciatura em Educação Física) - Instituto de Biociências, Universidade Estadual Paulista, Rio Claro, 2000.

FISCHER, R. M. B. Foucault e a análise do discurso em educação. Cadernos de Pesquisa, n. 144, p. 197-223, nov. 2001.

FOUCAULT, M. A ordem do discurso. 5. ed. São Paulo: Edições Loyola, 1999. . Arqueologia do saber. 5. ed. Rio de Janeiro: Forense Universitária, 1997. 
MEC. Parecer n. 0195/2003. Diretrizes Curriculares Nacionais dos cursos de graduação em Música, Dança, Teatro e Design. Disponível em: <http://portal.mec.gov.br/cne/ arquivos/pdf/CES_0195.pdf>. Acesso em: $1^{\circ}$ mar. 2013.

MENDES, M. G. A dança. 2. ed. São Paulo: Ática, 1987.

MINISTÉRIO DA EDUCAÇÃO. Parâmetros Curriculares Nacionais: Arte. Secretaria de Educação Fundamental. Brasília: MEC/SEF, 1997.

. Parâmetros Curriculares Nacionais: Educação Física. Secretaria de Educação Fundamental. Brasília: MEC/SEF, 1997.

. Decreto n. 6.096, de 24 de abril de 2007. Institui o Programa de Apoio a Planos de Reestruturação e Expansão das Universidades Federais - REUNI. Disponível em: <http://www.planalto.gov.br/ccivil_03/_ato2007-2010/2007/decreto/d6096.htm>. Acesso em: 1 mar. 2013.

OLIVEIRA, E. M. Docência universitária em arte: (auto)retratos da identidade docente-artista. Dissertação (Mestrado em Educação) - Universidade Federal de Goiás, Goiânia, 2010.

OSSONA, P. A Educação pela dança. São Paulo: Summus, 1988.

PEREIRA, M. L.; HUNGER D. A. C. F. Dança e Educação Física no Brasil: questões polêmicas. Revista Digital, Buenos Aires, ano 11, n. 96, mai. 2006.

SOMMER, L. H. A ordem do discurso escolar. Revista Brasileira de Educação. Campinas, v. 12, Autores Associados, 2007.

STRAZZACAPPA, M.; MORANDI, C. Entre a arte e a docência: a formação do artista da dança. São Paulo: Papirus, 2006.

UNIVERSIDADE LUTERANA DO BRASIL. Projeto Pedagógico - Licenciatura em Dança. Disponível em: <http://www.ulbra.br/danca/>. Acesso em: 3 mar. 2013.

UNIVERSIDADE FEDERAL DE SANTA MARIA. Projeto Político Pedagógico - Bacharelado. Pró-Reitoria de Graduação. Disponível em: <http://w3.ufsm.br/prograd/not. php?id=1037>. Acesso em: 3 mar. 2013.

UNIVERSIDADE FEDERAL DA BAHIA. Projeto Político Pedagógico - Licenciatura em Dança. Disponível em: < http://www2.ufba.br/ danca/>. Acesso em: 3 mar. 2013.

Projeto Político Pedagógico - Licenciatura. Pró-Reitoria de Graduação. Disponível em: <http://w3.ufsm.br/prograd/not.php?id=1037>. Acesso em: 3 mar. 2013. 
Marcelo de Andrade Pereira é professor do Departamento de Fundamentos da Educação da UFSM; mestre em Filosofia, UFRGS; mestre e doutor em Educação, UFRGS; editor associado da Revista Brasileira de Estudos da Presença; coordenador do FLOEMA - Núcleo de estudos em estética e educação, da UFSM; membro do GETEPE - Grupo de estudos em educação, teatro e performance, UFRGGS. Vice- -coordenador do GT 24 - Educação e Artes, da ANPED.

E-mail: doutorfungo@gmail.com

JoÃo BATISTA LIMA dE SouZA é graduado em Educação Física, UPF; mestre em Educação, UFSM; doutorando em Educação, UFSM; membro do FLOEMA - Núcleo de estudos em estética e educação, UFSM.

E-mail: jotabls@hotmail.com 